\title{
Taxonomic sufficiency in distinguishing natural spatial patterns on an estuarine shoreline
}

\author{
Megan N. Dethier ${ }^{1, *}$, G. Carl Schoch ${ }^{2}$ \\ ${ }^{1}$ Dept. of Biology and Friday Harbor Laboratories, University of Washington, Friday Harbor, Washington 98250, USA \\ ${ }^{2}$ Prince William Sound Science Center, 300 Breakwater Ave., Cordova, Alaska 99574, USA
}

\begin{abstract}
Studies of marine benthic communities have shown that pollution impacts can often be detected without identifying taxa to the species level, thus saving considerable time and cost. We tested whether differences among unpolluted intertidal communities along weak estuarine physical gradients could similarly be detected with various species aggregates. We used a spatially hierarchical sampling design to study species-rich, low-shore communities from pebble-sand beaches in Puget Sound, Washington. Previous research showed that weak north-south gradients in salinity, wave energy, and proportion of fine sediments correlate clearly with species richness of the benthic epibiota and macroinfauna. In this study, we found similar correlations with data aggregated to the family level but weaker correlations at higher levels (class, phylum, or trophic groupings). Multivariate analyses of community data at the species level show distinct separation among geographically distinct areas; similar spatial patterns are visible almost as clearly when data are gathered at lower resolution in the field or when species-level data are aggregated to families. Higher-level aggregations cause spatial patterns to become progressively less distinct. Much of this effectiveness of familylevel aggregation stems from the biota being family-rich but with few species per family. For this biota, monitoring programs using only families or other readily identifiable taxa should be able to detect many potential changes in community patterns in space or time. Incorporating occasional surveys using identification and analysis at the species level would add the capacity to examine biodiversity and possible within-family changes in species abundances.
\end{abstract}

KEY WORDS: Taxonomic sufficiency $\cdot$ Estuarine gradients $\cdot$ Species richness $\cdot$ Multivariate analyses · Monitoring $\cdot$ Benthic biota

\section{INTRODUCTION}

A variety of recent studies have considered the taxonomic levels at which spatial or temporal patterns related to pollution effects can be detected. Most have shown that analyses of species aggregates such as families or even orders are as good at detecting pollution effects as are species-level analyses, allowing substantial savings of time and taxonomic expertise (reviewed by Somerfield \& Clarke 1995, Olsgard et al. 1997, also Warwick 1988a,b, Rumohr \& Karakassis 1999, Mistri \& Rossi 2001, Pagola-Carte et al. 2002, Lasiak 2003). Most studies have been done along minimal environmental gradients, with anthropogenic disturbance being the major extrinsic factor affecting the biota. Organismal patterns are presumed to be closely linked to abiotic conditions such that differences in pollution level result in differences in the biota that can be seen even when species are aggregated. When the same inferences about patterns in nature can be drawn from both species and higher taxa information, the latter has been termed 'sufficient' (Ellis 1985) and the former even 'redundant' (Ferraro \& Cole 1992). Such data have been used to define pollution indicators that are whole families rather than species. This could be misleading since species within an aggregation have the capacity to function independently of each other and might undergo compensatory changes in response to a physical or chemical stressor (Frost et al. 1992). For example, one species might increase while another in 
the same family decreased; in this case, the familylevel aggregation would appear insensitive to that stress. But if most of the species within a higher taxonomic category respond similarly to a stress, then families can be good indicators.

In unpolluted systems, relatively few studies have assessed the ability of taxonomic aggregates to demonstrate the same spatial patterns seen at the species level. James et al. (1995) found that differences among depths in infaunal sand-habitat communities were detected just as well at the family level using both multivariate and univariate analyses. Chapman (1998) found broad groupings of biota of mangrove forests to illustrate among-habitat (tidal flushing) differences similarly to finer groupings. Lasiak (2003) found differences in rocky shore macrofauna among regions and between exploited and unexploited areas to be detectable at a variety of levels of taxonomic resolution. De Biasi et al. (2003) found similar results in detecting community differences along a sharp estuarine gradient, with relatively little loss of information until aggregated to higher than the family level.

In a pilot study for a program monitoring the long-term 'health' of the Puget Sound estuary (http://www2. wadnr.gov/nearshore/index.asp, G.C. Schoch \& M.N. Dethier unpubl. data), we found that multivariate analyses were capable of distinguishing unpolluted benthic communities from different intertidal substrate types (sand, gravel, mud) at the family level almost as readily as at the species level. If such taxonomic sufficiency can be demonstrated for more subtly different communities, e.g. the organisms inhabiting beaches of one substrate type along a mild estuarine gradient, then this could result in much reduced levels of cost and taxonomic expertise for shoreline monitoring. We have shown (Dethier \& Schoch 2005) that spatial patterns in diversity and community structure in one substrate type can be distinguished relative to an estuarine gradient when the taxonomic resolution is primarily at the species level. Here we hypothesize that aggregating biotic community data into higher taxonomic levels and trophic groups will result in spatial patterns different from those obtained by species-level analysis of the data.

We studied pebble-sand beaches along the northsouth axis of Puget Sound, Washington, all of which were relatively undisturbed and unpolluted. Our previous work (Dethier \& Schoch 2005) showed that this north-south axis corresponds to a relatively shallow estuarine gradient of salinity (about 3 psu higher in the north), sea surface temperature (about $3^{\circ} \mathrm{C}$ lower in the north), wave energy (somewhat higher in the north), and fine sediments (fewer in the north). Paralleling this gradient is that of species richness of shoreline organisms, which increases gradually from south to north. Similarities in physical conditions and biotic assem- blages (primarily identified to the species level) decrease with increasing distance among sites. The combination of weak physical gradients and clear biotic community patterns at the species level offered a good opportunity to test the level of taxonomic sufficiency for a monitoring program in a natural environment.

\section{METHODS}

We used a nested sampling design to quantitatively assess patterns of benthic nearshore populations and communities at spatial scales ranging from meters to tens of kilometers within the Puget Sound region. At the largest scale, we divided the region into 3 basins to capture both major and minor estuarine boundaries. The major boundary is a bathymetric sill at the Tacoma Narrows (Fig. 1), which creates a hydrographic constriction to the south basin. A minor hydrographic boundary separates the south central basin from the north central basin near Elliot Bay (Fig. 1). At the smallest scale, we chose to sample the predominant beach habitat type in Puget Sound, a mixture of sand, pebbles, and small cobbles. Our design relied on locating shore segments that were physically similar in terms of substrate size, slope angle, and wave energy at scales greater than $50 \mathrm{~m}$. Three randomly selected segments within a distance of $3 \mathrm{~km}$ provided spatial replicates for a site. Similarly, we selected 3 sites within each of five $15 \mathrm{~km}$ areas (squares in Fig. 1). The resulting levels of nesting are segments within sites, sites within areas, and areas within basins for a $45 \times 15 \times 5 \times 3$ design (Table 1 ), more fully described in Dethier \& Schoch (2005).

Biological sampling was conducted during spring tides in May and June of 1999. The low zone of each segment was sampled at the tidal datum of mean lower low water (MLLW) where organisms are submerged ca. $90 \%$ of the time. This ensured that samples were collected at elevations with the same mean annual submersion times. A surveying level and stadia rod were used to locate the appropriate transect elevation relative to the predicted tide at the time of the measurement. These measurements were subsequently compared to the actual tide and were typically within $\pm 0.15 \mathrm{~m}$ of the target elevation. Our samples, taken at low tide, consisted of the mean species abundances from 10 randomly spaced sample units along a $50 \mathrm{~m}$ horizontal transect at each of the 45 shore segments. A pilot study in 1998 showed that 10 sample units accounted for $95 \%$ of the richness per transect with ca. $80 \%$ accounted for by the first 6 sample units. Therefore, additional sample units would not appreciably increase the estimates of segment richness. Each sample unit consisted of a $0.25 \mathrm{~m}^{2}$ quadrat to quantify abundance of surface macroflora and fauna, plus a $10 \mathrm{~cm}$ diameter $\times 15 \mathrm{~cm}$ deep core for macroinfauna. Per- 


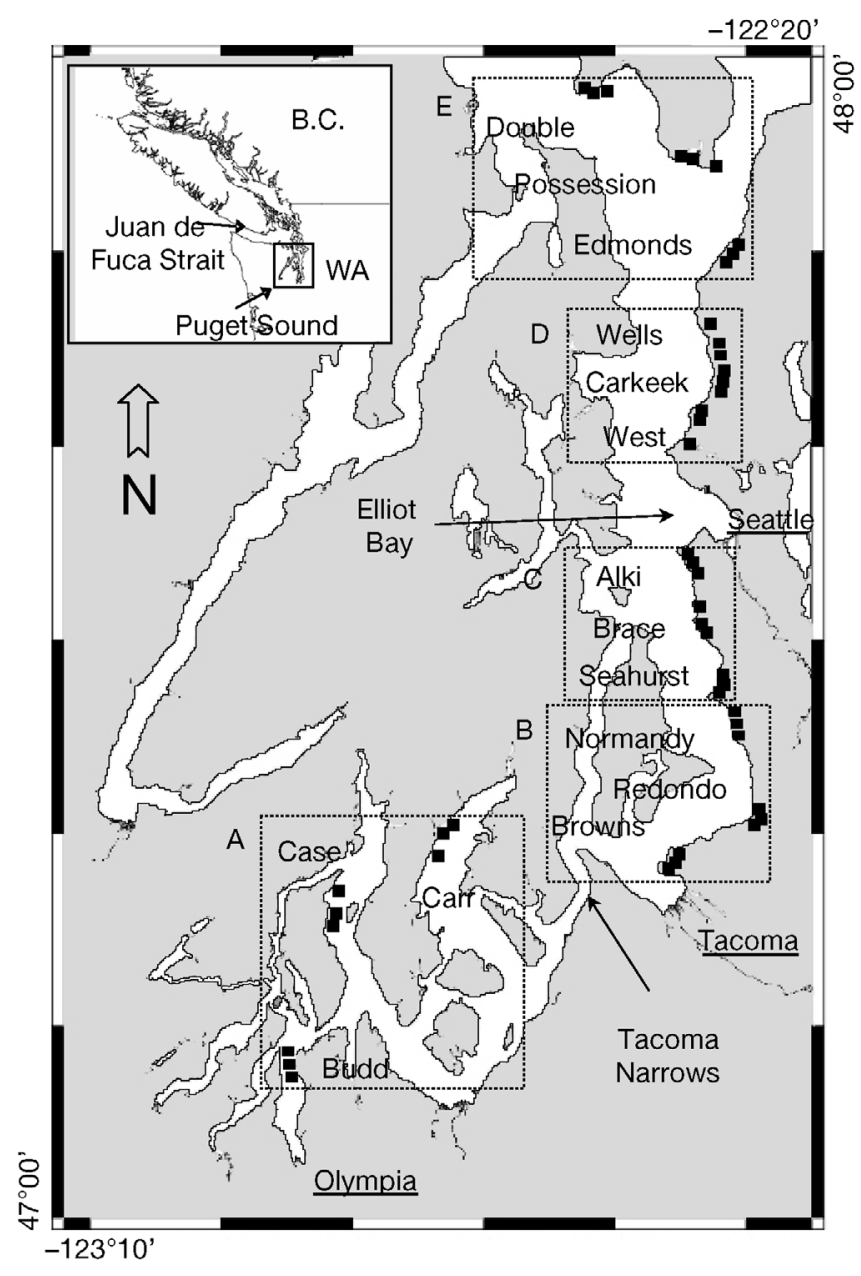

Fig. 1. Nested study sites in Puget Sound, Washington. There were 3 replicate segments ( $\square$ ) in a site, 3 sites (named) in an area, and 5 (boxed, A-E) areas. Segments are listed in Table 1

cent cover was estimated for all sessile taxa in the quadrats, and all motile epifauna (organisms $>$ ca. $3 \mathrm{~mm}$ ) were counted. Core samples were washed through $2 \mathrm{~mm}$ mesh sieves, thereby excluding meiofauna, juveniles of some worms, and adults of smaller crustaceans such as cumaceans and harpacticoids. Smaller sieve sizes clogged with this pebbly-sandy sediment. Infaunal taxa were preserved in formalin and returned to the laboratory for identification. Taxonomic references were Kozloff (1996) for invertebrates and Gabrielson et al. (2000) for macroalgae.

The finest taxonomic resolution used in field sampling and laboratory identification was species level, although some difficult taxa were only identifiable to genus or higher levels (e.g. Pagurus spp., Phylum Nemertea). For tests of taxonomic aggregation, the second level used 'low-resolution' categories, defined as those into which a non-specialist could unambiguously place epibiota in the field or infauna in the lab. They include species in some cases (where readily recogniz-
Table 1. Nested sampling design at Puget Sound, Washington, with sample locations from south to north (sites shown in Fig. 1)

\begin{tabular}{|c|c|c|c|c|c|}
\hline \multirow[t]{2}{*}{ Basin } & \multirow[t]{2}{*}{ Area } & \multirow[t]{2}{*}{ Site } & \multirow{2}{*}{ Segment } & \multicolumn{2}{|c|}{ Position } \\
\hline & & & & Long. & Lat. \\
\hline \multirow[t]{9}{*}{ South } & \multirow[t]{9}{*}{ Olympia } & \multirow[t]{3}{*}{ Budd Inlet } & A1 & 47.11 & -122.92 \\
\hline & & & A2 & 47.13 & -122.92 \\
\hline & & & A3 & 47.14 & -122.92 \\
\hline & & \multirow[t]{3}{*}{ Case Inlet } & A4 & 47.28 & -122.86 \\
\hline & & & A5 & 47.27 & -122.86 \\
\hline & & & A6 & 47.25 & -122.86 \\
\hline & & \multirow[t]{3}{*}{ Carr Inlet } & A7 & 47.29 & -122.75 \\
\hline & & & A8 & 47.34 & -122.73 \\
\hline & & & A9 & 47.35 & -122.71 \\
\hline \multirow{18}{*}{$\begin{array}{l}\text { South } \\
\text { Central }\end{array}$} & \multirow[t]{9}{*}{ Tacoma } & \multirow[t]{3}{*}{ Browns Point } & B1 & 47.30 & -122.44 \\
\hline & & & B2 & 47.31 & -122.44 \\
\hline & & & B3 & 47.31 & -122.43 \\
\hline & & \multirow[t]{3}{*}{ Redondo } & B4 & 47.35 & -122.32 \\
\hline & & & B5 & 47.35 & -122.32 \\
\hline & & & B6 & 47.35 & -122.33 \\
\hline & & \multirow[t]{3}{*}{ Normandy } & B7 & 47.42 & -122.35 \\
\hline & & & B8 & 47.43 & -122.35 \\
\hline & & & B9 & 47.43 & -122.35 \\
\hline & \multirow{9}{*}{$\begin{array}{l}\text { South } \\
\text { Seattle }\end{array}$} & \multirow[t]{3}{*}{ Seahurst } & $\mathrm{C} 1$ & 47.46 & -122.37 \\
\hline & & & $\mathrm{C} 2$ & 47.89 & -122.37 \\
\hline & & & C3 & 47.50 & -122.38 \\
\hline & & \multirow[t]{3}{*}{ Brace } & $\mathrm{C} 4$ & 47.51 & -122.39 \\
\hline & & & C5 & 47.51 & -122.39 \\
\hline & & & C6 & 47.53 & -122.40 \\
\hline & & \multirow[t]{3}{*}{ Alki } & $\mathrm{C} 7$ & 47.54 & -122.40 \\
\hline & & & $\mathrm{C} 8$ & 47.57 & -122.41 \\
\hline & & & C9 & 47.57 & -122.41 \\
\hline \multirow{18}{*}{$\begin{array}{l}\text { North } \\
\text { Central }\end{array}$} & North & \multirow[t]{3}{*}{ West Point } & D1 & 47.67 & -122.42 \\
\hline & Seattle & & D2 & 47.69 & -122.41 \\
\hline & & & D3 & 47.70 & -122.40 \\
\hline & & \multirow[t]{3}{*}{ Carkeek } & D4 & 47.72 & -122.38 \\
\hline & & & D5 & 47.72 & -122.38 \\
\hline & & & D6 & 47.74 & -122.38 \\
\hline & & \multirow[t]{3}{*}{ Wells Point } & D7 & 47.76 & -122.38 \\
\hline & & & D8 & 47.75 & -122.39 \\
\hline & & & D9 & 47.78 & -122.40 \\
\hline & Whidbey & Edmonds & E1 & 47.83 & -122.37 \\
\hline & & & E2 & 47.83 & -122.36 \\
\hline & & & E3 & 47.84 & -122.35 \\
\hline & & Possession & E4 & 47.90 & -122.38 \\
\hline & & & E5 & 47.91 & -122.41 \\
\hline & & & E6 & 47.91 & -122.43 \\
\hline & & Double Bluff & E7 & 47.97 & -122.52 \\
\hline & & & E8 & 47.97 & -122.52 \\
\hline & & & E9 & 47.97 & -122.54 \\
\hline
\end{tabular}

able), families for most infauna and for fishes (the few taxa found under cobbles), functional groups for most algae, and phyla for a few groups (e.g. Platyhelminthes). The higher taxonomic levels of data aggregation tested were family (for all taxa except those already assigned only to higher levels), class, and phylum. Finally, we assigned all taxa to trophic groups based on Fauchald \& Jumars (1979) and Kozloff (1983). A complete list of taxa and trophic assignments is given in Dethier \& Schoch (2005). 
Table 2. Summary of taxonomic resolutions of samples (high and low) and taxonomic aggregations used for hypothesis tests of significant differences among patterns of diversity and community structure. Function = algal functional groups

\begin{tabular}{|lccccc|}
\hline & High & Low & \multicolumn{3}{c|}{ High resolution aggregates } \\
& resolution & resolution & Family & Class & Phylum \\
\hline Species & 126 & 25 & - & - & - \\
Genera & 29 & 25 & - & - & - \\
Families & 7 & 43 & 90 & - & - \\
Classes & 1 & 2 & 1 & 16 & - \\
Phyla & 2 & 2 & 2 & 2 & 13 \\
Function & - & 8 & - & - & - \\
Total & 165 & 105 & 93 & 18 & 13 \\
a Or Division for algae & & & & \\
\hline
\end{tabular}

ratulids, 4 capitellids) and to a lesser extent in the arthropods (e.g. 5 pinnotherid crabs) and mollusks (6 tellinid bivalves). Our 'low-resolution' dataset had 105 taxa, with 25 species, 25 genera, 43 families, 2 classes, 2 phyla, and 8 functional groups (for algae).

Patterns of relative taxon richness at each level of resolution and aggregation, with respect to the along-axis estuarine gradient of Puget Sound, were qualitatively evaluated from plots (Fig. 3) and with spatial regressions (Table 3). The regression tests were all significant, with the strongest correlations between richness and spatial location at the high

Data were analyzed for differences in relative taxon richness. Different levels of taxonomic aggregation were plotted, and hypotheses (of no spatial correlation) were tested using a local regression fit (LOESS) with longitude and latitude as predictors for regional scale spatial trends. The fully nested ANOVA of Sokal \& Rohlf (1995) was used to test the hypotheses of no difference for sites nested within areas, areas nested within basins, and among basins for each level of taxonomic resolution and level of aggregation. The multivariate analyses methods of Clarke \& Warwick (1994) were used to test for spatial patterns in community structure. The data matrix of taxon abundances at the segment level was square-root transformed and we used the ordination technique of non-metric multidimensional scaling (MDS) to group communities based on a Bray-Curtis similarity matrix. Two-way nested analyses of similarity (ANOSIM, Clarke \& Green 1988) were used to test for differences among sites nested within areas and among areas. Hypotheses (of no difference) were also tested between area pairs. With only 3 segments in each site, these nested tests could not be run at the segment scale. Spearman rank correlations between each level of aggregation and the high-resolution species-level data were determined using the RELATE module in PRIMER software (Clarke \& Gorley 2001).

\section{RESULTS}

Numbers of taxa in different categories are summarized in Table 2. At the highest level of resolution, we found 165 taxa. These were distributed among 126 species, 29 genera, 90 families, 16 classes, and 13 phyla (or divisions for algae). The number of species per family ranged widely (Fig. 2); most (72) families had only 1 species represented. The most species-rich families were in the polychaetes (e.g. 8 spionids, 6 cir- resolution and progressively decreasing with each level of aggregation. The Wells site had anomalously low richness; these segments were physically somewhat dissimilar to the surrounding ones (Dethier \& Schoch 2005) and have a history of anthropogenic stressors (Dethier \& Schoch 2000). Table 3 also lists the results of nested ANOVAs for tests of differences at the site, area, and basin scales. Differences in richness among sites were significant only at the high and low resolutions of taxonomic identification and became progressively less different with each level of aggregation. The greatest change in the F-statistics occurred between the family and class aggregations. High and low resolutions and the family level of aggregation were significantly different among areas. Neither of the resolutions and none of the aggregations were significantly different at the basin scale, although to some extent this could be attributed to the low degrees of freedom.

Comparisons of community similarity were made using the Segment-scale data to determine differences among sites within areas and among areas at high (45 samples $\times 165$ taxa) and low $(45 \times 105)$ resolution and using aggregation levels of family $(45 \times 93)$, class $(45 \times$ $18)$, and phylum $(45 \times 13)$. The plots in Fig. 4 show the 2-dimensional solutions of the MDS ordinations along with the stress values or goodness-of-fit (lower stress

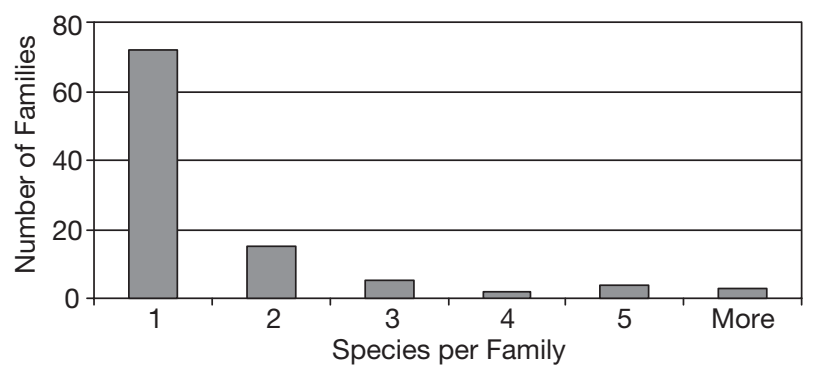

Fig. 2. Number of taxonomic families represented in sampled biota and number of species per family. 'More' data points $=6$, 6 , and 8 species per family 
Table 3. Summary of differences in taxon richness among sites, areas and basins at different resolutions of taxonomic identification (high and low), different levels of taxonomic aggregation (family, class, phylum), and trophic level, using nested ANOVA. Spatial regression was used to test for regional scale differences. Significant differences are shown in bold

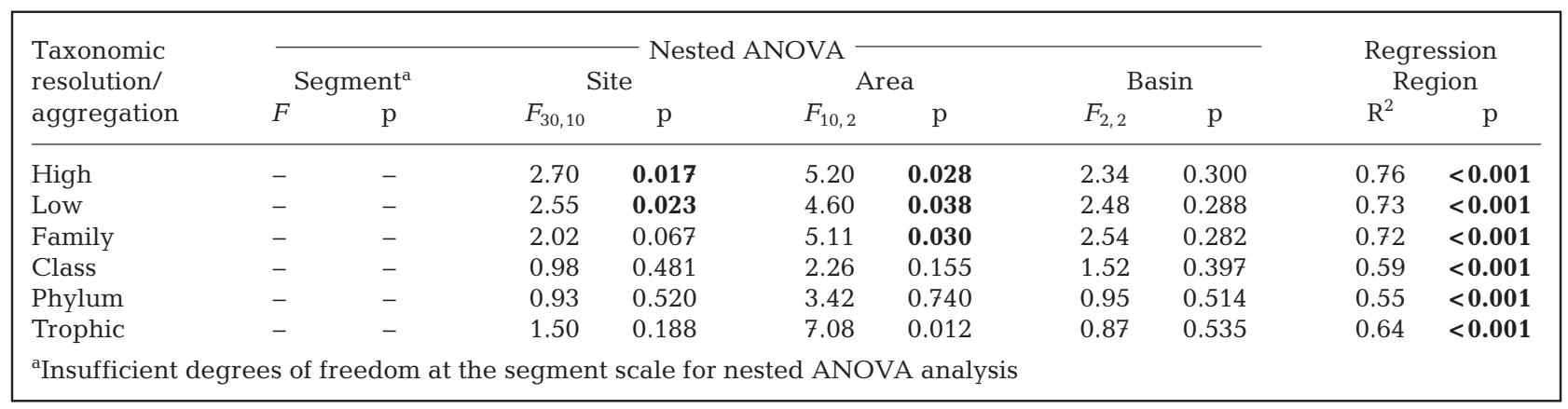

indicates a better solution). Data points are labeled by segment code (Table 1) and represent the sampled community in ordination space. At the high resolution, beach segments are generally grouped closely with (i.e. are biologically most similar to) others at the same site (e.g. the 3 beaches at Budd Inlet or Alki), although some segment groups are less similar (e.g. Case Inlet). For the high-resolution data (A), low-resolution data
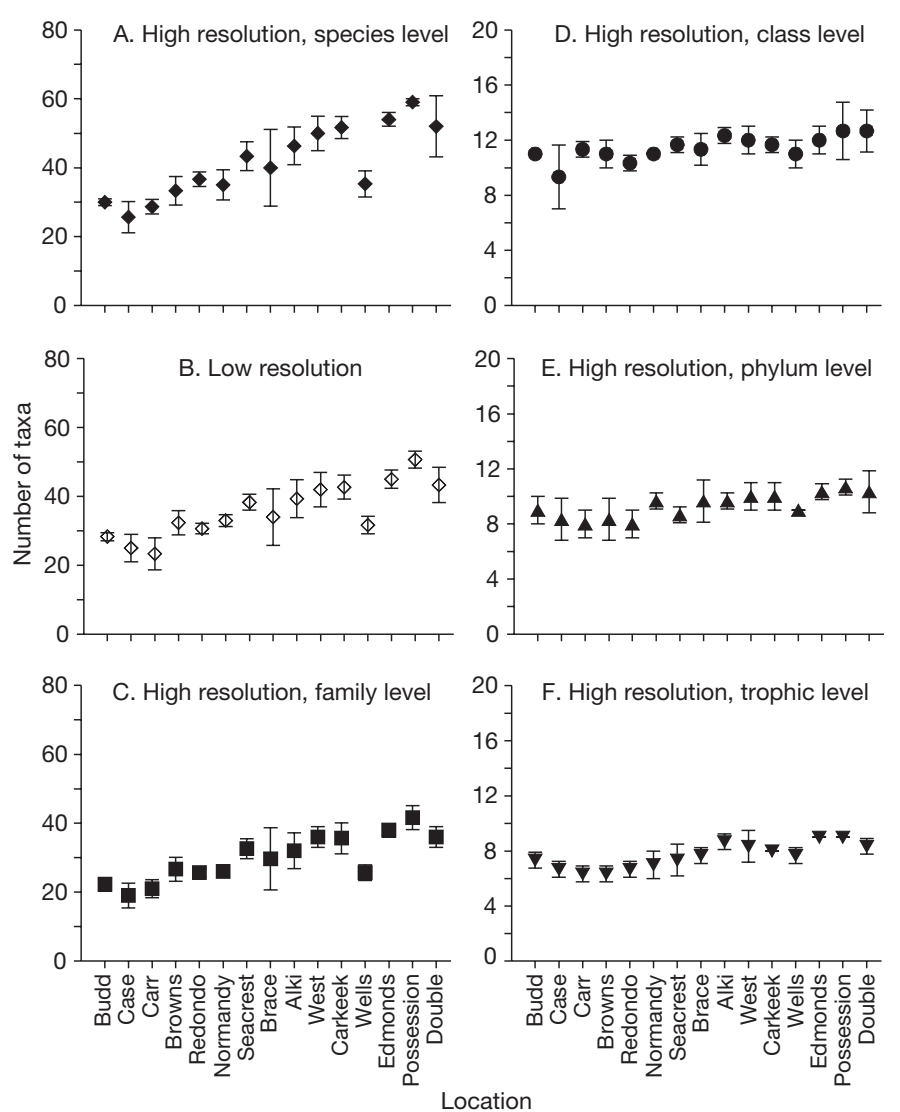

Fig. 3. Mean number of taxa at 2 levels of field identification: (A) high and (B) low resolution, and 4 aggregation levels of the high-resolution data: (C) family, (D) class, (E) phylum, and $(\mathrm{F})$ trophic level. Error bars $=1 \mathrm{SD}$
(B), and family-level aggregation (C) the South Sound communities (Budd, Carr, and Case Inlets) are clearly distinct from each other and from all other communities. In addition, all the segments are generally aligned from left (south) to right (north), paralleling the estuarine gradient of Puget Sound. Collapsing the data into higher taxonomic levels (class and phylum; Fig. $4 \mathrm{D}, \mathrm{E})$ results in a steady loss in ability to detect these patterns, and the Global R values drop substantially (Table 4D,E). Even the usually clear separation of the south basin sites from the central basin sites is lost. This is not surprising, since relatively few phyla are present in these samples overall, so the ability to distinguish beaches at that level is poor.

Differences in community similarity among sites and areas for each level of taxonomic resolution and aggregation were tested using a balanced 2-way nested analysis of similarity (Nested ANOSIM: Table 4). Tests for significance used the Global R statistic with 999 permutations (where $\mathrm{R}=1$ represents maximal separation). Pairwise comparisons used 10 permutations and thus could only qualitatively test for significant differences in community structure among areas (Table 4). Between-site differences were all highly significant except for the family level (Table 4C). Area-scale differences were all significant except for the trophic level (Table 4F). Qualitative evaluations of the R-statistics suggest that the greatest differences for both site and area were at the high and low resolutions. The family aggregation level was the least likely to detect differences among sites but the most likely to detect differences among areas. Among-site and among-area differences were the least likely to be detected using the class, phylum, and trophic aggregation levels. None of the pairwise comparisons was significantly different, but the low number of possible permutations makes this inconclusive. However, qualitative evaluations show that communities among areas become more different with distance for both high and low resolutions of taxonomic identification with only a slight 
A. High resolution, species level

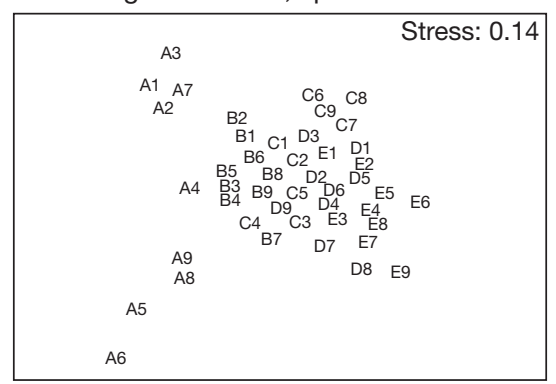

B. Low resolution

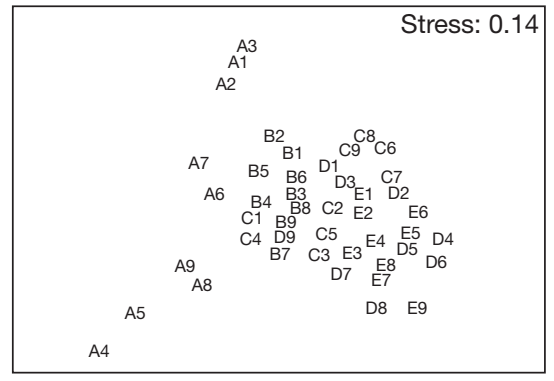

C. High resolution, family level

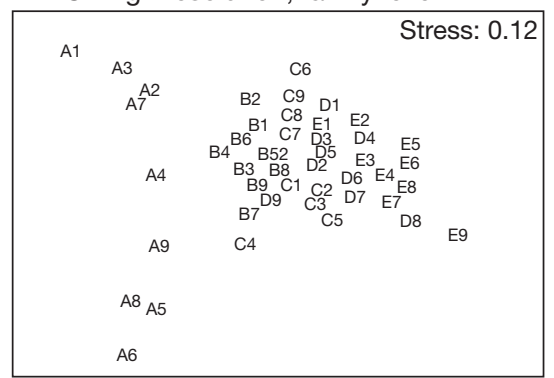

F.

F. High resolution, trophic leve

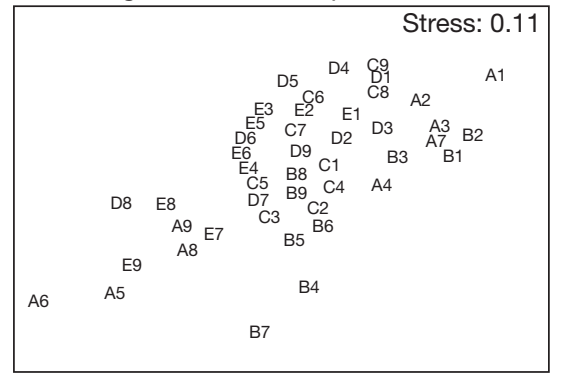

Fig. 4. Two-dimensional solutions for ordinations of community similarity. Segment codes are listed in Table 1. Plots show results for 2 levels of field identification, (A) high and (B) low resolution, and 4 aggregation levels of high-resolution data: (C) family, (D) class, phylum (E), and (F) trophic level

decrease in the magnitude of change between high and low resolutions. The R-values of pairwise tests between areas suggest the greatest community differences at the family level of aggregation. As with the nested analyses, between-area differences were the least likely to be detected using the class, phylum, and trophic aggregation levels. Spearman correlations between similarity matrices using the RELATE module of PRIMER software were all highly significant. The strongest correlation was between the high- and low-resolution data, and the correlations became progressively weaker with each successive level of aggregation.

\section{DISCUSSION}

In our previous study of linkages among organisms and geophysical features (Dethier \& Schoch 2005), we used high-resolution, largely species-level data to demonstrate that differences in pebble beach communities exist along natural physical gradients. The current study tested whether using lower-resolution groupings is sufficient to see such community differences. For the macroorganisms in a common habitat type in Puget Sound, we found that both species and taxonomic aggregations, especially families, are tied to natural environmental gradients. Our study differs from the few others on natural (i.e. unimpacted) gradients (James et al. 1995, Chapman 1998, De Biasi et al. 2003) in its inclusion of both epibiota and infauna and its focus on an unstudied but common habitat type, as well as in the relative subtlety of the natural gradients. De Biasi et al. (2003) suggest that the family level is taxonomically sufficient for habitats with 'strong gradients in ecophysiological stress', but our results go farther in suggesting that even weak estuarine gradients (in wave energy, fine sediments, temperature, and salinity) can drive family-level patterns. Higher-level aggregations (e.g. to class or phylum) correlate much more weakly with the estuarine gradient (Fig. 3, Table 3) and are relatively ineffective at distinguishing communitylevel differences among geographic areas that are distinct at the species level (Table 4). Thus, at least in these systems (along with the various pollution studies, e.g. Olsgard et al. 1997), the family level can be sufficient to detect change caused by either natural or anthropogenic factors.

Given that there are few species in most families in our database (Fig. 2), it is likely that families 'shift' among beaches simply because species shift among beaches. In the multispecies families, often one species was found commonly (e.g. Macoma inquinata in the tellinid bivalves) while other species were represented only by few individuals at few sites, so that there were no real dominance shifts. For example, of the 8 spionid species, only 2 were found at more than 2 sites. Spionids overall were virtually absent from the south sound sites, driving some of the species-level separation of these from the central sound sites. Of the 4 capitellid species, 2 were found throughout the sound and the other 2 were 'added' in the central sites only. Thus there is some evidence that species within families shift in response to subtle physical variables, i.e. that species replace each other along a minor physical gradient 
Table 4. Summary of community similarity analyses using 2-way nested ANOSIM (with 999 permutations) for comparisons among sites within areas and among areas, and pairwise tests between areas (with 10 permutations), for (A) high and (B) low taxonomic resolutions of samples, and $(\mathrm{C}-\mathrm{F}) 4$ levels of aggregations of the high resolution samples. Comparisons between high and low resolutions of taxonomic identification, as well as between each level of taxonomic aggregation and species level data, are shown by Spearman rank correlations using RELATE (PRIMER software, Clarke \& Gorley 2001)

\begin{tabular}{|c|c|c|c|c|c|c|c|c|c|c|c|}
\hline \multicolumn{6}{|c|}{$\begin{array}{c}\text { Among: Sites R: } 0.616 ; \mathrm{p}<0.001 \\
\text { Areas R: } 0.564 ; \mathrm{p}<0.001 \\
\\
\end{array}$} & \multicolumn{6}{|c|}{$\begin{aligned} \text { Among: } & \text { Sites R: } 0.381 ; \mathrm{p}<0.002 \\
& \text { Areas R: } 0.160 ; \mathrm{p}<0.032 \\
& \text { Pairwise R-statistic }\end{aligned}$} \\
\hline Area & A & B & C & D & E & Area & A & B & C & D & E \\
\hline A & 0.000 & 0.630 & 0.778 & 0.741 & 0.936 & A & 0.000 & 0.222 & 0.185 & 0.222 & 0.296 \\
\hline B & & 0.000 & 0.370 & 0.926 & 0.963 & $\mathrm{~B}$ & & 0.000 & -0.111 & 0.000 & 0.148 \\
\hline $\mathrm{C}$ & & & 0.000 & 0.222 & 0.556 & $\mathrm{C}$ & & & 0.000 & 0.185 & 0.222 \\
\hline $\mathrm{D}$ & & & & 0.000 & 0.111 & $\mathrm{D}$ & & & & 0.000 & -0.111 \\
\hline \multirow[t]{2}{*}{$\mathrm{E}$} & & & & & 0.000 & $\mathrm{E}$ & & & & & 0.000 \\
\hline & & & & & & \multicolumn{6}{|c|}{ Spearman correlation: $0.653 ; \mathrm{p}<0.001$} \\
\hline \multicolumn{6}{|c|}{ B. Low resolution } & \multicolumn{6}{|c|}{ E. High resolution, phylum level } \\
\hline Among: & $\begin{array}{l}\text { Sites } \\
\text { Areas }\end{array}$ & $\begin{array}{r}.651 ; \mathrm{p} \\
.452 ; \mathrm{p} \\
\text { Pail }\end{array}$ & $\begin{array}{l}0.001 \\
0.001 \\
\text { ise R-s }\end{array}$ & stic & & \multicolumn{6}{|c|}{$\begin{array}{ll}\text { Among: } & \text { Sites R: } 0.398 ; \mathrm{p}<0.001 \\
& \text { Areas R: } 0.219 ; \mathrm{p}=0.015\end{array}$} \\
\hline Area & A & B & $\mathrm{C}$ & D & E & Area & A & B & $\mathrm{C}$ & D & E \\
\hline A & 0.000 & 0.407 & 0.519 & 0.519 & 0.778 & A & 0.000 & 0.185 & 0.111 & 0.222 & 0.333 \\
\hline $\mathrm{B}$ & & 0.000 & 0.333 & 0.815 & 0.926 & $\mathrm{~B}$ & & 0.000 & 0.000 & 0.111 & 0.500 \\
\hline $\mathrm{C}$ & & & 0.000 & 0.074 & 0.519 & $\mathrm{C}$ & & & 0.000 & 0.037 & 0.333 \\
\hline $\mathrm{D}$ & & & & 0.000 & 0.019 & $\mathrm{D}$ & & & & 0.000 & -0.074 \\
\hline $\mathrm{E}$ & & & & & 0.000 & $\mathrm{E}$ & & & & & 0.000 \\
\hline Spearma & n correl & on: 0.94 & $\mathrm{p}<0.0$ & & & Spear & correl & on: 0.63 & $; \mathrm{p}<0.0$ & & \\
\hline \multicolumn{6}{|c|}{ C. High resolution, family level } & \multicolumn{6}{|c|}{ F. High resolution, trophic level } \\
\hline \multirow[t]{3}{*}{ Among: } & \multirow{2}{*}{\multicolumn{5}{|c|}{$\begin{array}{l}\text { Sites R: }-0.212 ; \mathrm{p}=0.998 \\
\text { Areas R: } 0.884: \mathrm{p}<0.001\end{array}$}} & \multirow{2}{*}{\multicolumn{6}{|c|}{$\begin{array}{ll}\text { Among: } & \text { Sites R: } 0.542 ; \mathrm{p}<0.001 \\
& \text { Areas R: } 0.077 ; \mathrm{p}=0.248\end{array}$}} \\
\hline & & & & & & & & & & & \\
\hline & \multicolumn{5}{|c|}{ Pairwise R-statistic } & \multicolumn{6}{|c|}{ Pairwise R-statistic } \\
\hline Area & A & B & $\mathrm{C}$ & $\mathrm{D}$ & E & Area & A & B & $\mathrm{C}$ & $\mathrm{D}$ & E \\
\hline A & 0.000 & 1.000 & 1.000 & 1.000 & 1.000 & A & 0.000 & 0.185 & 0.370 & 0.148 & 0.111 \\
\hline B & & 0.000 & 0.926 & 1.000 & 1.000 & $\mathrm{~B}$ & & 0.000 & -0.037 & 0.037 & 0.111 \\
\hline $\mathrm{C}$ & & & 0.000 & 0.963 & 1.000 & $\mathrm{C}$ & & & 0.000 & -0.185 & 0.074 \\
\hline $\mathrm{D}$ & & & & 0.000 & 1.000 & $\mathrm{D}$ & & & & 0.000 & -0.222 \\
\hline $\mathrm{E}$ & & & & & 0.000 & $\mathrm{E}$ & & & & & 0.000 \\
\hline \multicolumn{6}{|c|}{ Spearman correlation: $0.892 ; \mathrm{p}<0.001$} & \multicolumn{6}{|c|}{ Spearman correlation: $0.534 ; \mathrm{p}<0.001$} \\
\hline
\end{tabular}

while it takes a larger gradient to cause a shift to a new family. The overall similarity of species- and familylevel ordinations, however (Table 4C), shows that most of the spatial patterns seen are driven by the shifts (or additions) of families along the north-south gradient.

In our intertidal monitoring program in Puget Sound, much of the time and expense of processing infaunal samples is in identifying polychaetes to species in the laboratory; identifying them to family is quite simple and rapid. Field data collection (of surface biota) is most rapidly done not at the taxonomic/family level but instead using 'low-resolution' categories, which group some species by family and others (especially algae) by functional group, which can be distinguished by non-specialists. 'Low-resolution' categories are actually more powerful than family-level groupings at distinguishing the biota among sites within areas
(Table 4B,C) but are less effective at distinguishing among areas. We thus conclude that gathering data using the low-resolution categories in the field and identifying infauna to the family level in the lab is a reasonable alternative to the more time-consuming species-level monitoring. Use of these categories should be sufficient to detect both gross changes (e.g. loss of whole families), and more subtle among-site differences (e.g. within central Sound). A reasonable long-term scenario might involve annual monitoring of most sites at this lower level of resolution, with periodic (e.g. every 3 to $5 \mathrm{yr}$ ) gathering of data at the species level to allow the most powerful examination of trends in species richness. In addition, if there were reason to suspect that a given beach or region was suffering from some new stressor (e.g. change in sediment supply due to hardening of eroding bluffs or change in 
salinity due to unusual precipitation), then data could be gathered at the species level to check for more subtle biotic changes, e.g. species replacements within families or functional groups.

Anthropogenic impacts may overwhelm faunal differences that might otherwise be seen along such geophysical gradients. Olsgard et al. (1997) found that environmental variables like depth and sediment grain size did not correlate with the spatial biotic patterns seen, whereas various parameters relating to the pollution source (an oil drilling platform) did. They also found that their statistical transformations generally had a greater effect on their ability to detect impacts than did changing the level of taxonomic identification. Chapman (1998) and Lasiak (2003) also found that the type of transformation altered patterns of variability with sites, which may be important for some research programs. Other studies (e.g. Mistri \& Rossi 2001) found the types of transformations used in multivariate analyses to make little difference in the ability to detect patterns. We found that most of the spatial patterns (e.g. among-site differences) illustrated here with square-root transformations were also visible with 4th root transformations of the data (G.C. Schoch \& M.N. Dethier unpubl. data).

The major benefit of being able to detect patterns (natural or anthropogenic) at higher taxonomic levels is the clear savings in time and expertise needed. We did not do a quantitative comparison of costs of different analyses, but Ferraro \& Cole (1995) and De Biasi et al. (2003) both found that the cost of family-level identification was 50 to $55 \%$ less than species-level identification. These figures will clearly vary greatly with number of species per family, types of organisms present (in taxonomically straightforward vs. difficult families), and type of taxonomic expertise available. Identification to the family level also avoids errors in identification, which are much more common at the species level. In addition, Ferraro \& Cole (1990) and Frost et al. (1992) suggested that grouping animals to higher taxa may dampen natural variability in faunal patterns, i.e. fluctuations in the abundances of individual species, thus increasing statistical power to assess small pollution impacts. Savings in effort put into taxonomic detail can profitably be transferred to field sampling effort. When organisms are patchy (as is usually the case), Chapman (1998) points out that it is probably more important to collect many replicates at different spatial and/or temporal scales than to sort and identify taxa to a high resolution.

Another reason to do family-level analyses is that in most cases we have little information on the life history and ecology of the species (especially the less common ones), so that we do not necessarily gain an improved ability to interpret patterns when we analyze to the species level (James et al. 1995). A practical solution in many cases may be to store samples in the long term, in the expectation that future analyses could be done at a finer level of taxonomic resolution if we learn more about sensitivities of particular species.

At this time, no studies have clearly identified the processes that enable taxonomic aggregations to 'work' in detecting spatial patterns, although a variety of theories are discussed in Olsgard et al. (1997). De Biasi et al. (2003) suggested that anthropogenic effects modify communities at higher taxonomic levels than do natural environmental variables because species cannot rapidly evolve in response to pollution events, but this cannot explain our results with natural gradients. Warwick (1988b) suggested that 'gradients in natural environmental variables, such as water depth and sediment granulometry, are more likely to influence the fauna by species replacement than by changes in proportions of major taxa', but this does not appear to be the case in our data. Because our communities are taxonomically diverse at the family level, with most families having only 1 to 2 species, similar patterns are likely to be found at the 2 levels.

The major tradeoff of analyses done only at higher levels of aggregation is the potential loss of important information visible only at the species level (e.g. site to site differences, Table 3). Like other authors (Somerfield \& Clarke 1995, De Biasi et al. 2003), we do not presume that species-level information has no added value. It enables the separation of species abundances into trophic categories and examination of abundance/ biomass curves and overall 'biodiversity' (Rumohr \& Karakassis 1999). Some sites with low diversity at the family level may have very high species diversity (Altaba 1997). The loss of information will depend in part on how similar ecologically the species within an aggregate are. Clarke \& Warwick (1998) found that several species within taxa and functional groups (e.g. deposit-feeding polychaetes) appear to react in similar ways to environmental variability (for both polluted and unpolluted areas). In contrast, Rakocinski et al. (1997) found that species-level analyses were very useful for understanding community shifts relative to a contamination gradient in their system, because even within a group (e.g. capitellids) there were fine-scale differences in species relationships to contaminants. Ponti \& Abbiata (2004) also noted that sensitivity (e.g. to pollution) can change dramatically within a genus or family. These apparent contradictions may lie in how subtle the differences in the ecosystems under study are; Rakocinski et al. (1997) found that finer-scale gradients may require analysis at higher levels of taxonomic resolution. Frost et al. (1992) suggested that effective indicators of stress may comprise intermediate levels of aggregation (e.g. genus or family rather 
than either species or order), which can provide the best combination of sensitivity and variability. We have shown that aggregating taxa is useful for seeing patterns that correlate with subtle geophysical factors and may be a useful procedure in monitoring programs.

Acknowledgements: We thank H. Berry and J. Ruesink for stimulating discussions and partnership in the field. We gratefully acknowledge funding, logistical support, and field assistance from the staff of the Nearshore Habitat Program, Washington Dept. of Natural Resources. MND thanks the director and staff of the Friday Harbor Laboratories for space and support and L. Harris and C. Staude for taxonomic assistance. Three anonymous reviewers spurred significant improvement in the manuscript.

\section{LITERATURE CITED}

Altaba CR (1997) Documenting biodiversity: the need for species identifications. Trends Ecol Evol 12:358-359

Chapman MG (1998) Relationships between spatial patterns of benthic assemblages in a mangrove forest using different levels of taxonomic resolution. Mar Ecol Prog Ser 162: 71-78

Clarke KR, Gorley N (2001) Primer v5. PRIMER-E, Plymouth

Clarke KR, Green RH (1988) Statistical design and analysis for a 'biological effects' study. Mar Ecol Prog Ser 46: 213-226

Clarke KR, Warwick RM (1994) Change in marine communities: an approach to statistical analysis and interpretation. Plymouth Marine Laboratory, Plymouth

Clarke KR, Warwick RM (1998) Quantifying structural redundancy in ecological communities. Oecologia 113:278-289

De Biasi AM, Bianchi CN, Morri C (2003) Analysis of macrobenthic communities at different taxonomic levels: an example from an estuarine environment in the Ligurian Sea (NW Mediterranean). Estuar Coastal Shelf Sci 58: 99-106

Dethier MN, Schoch GC (2000) The shoreline biota of Puget Sound: extending spatial and temporal comparisons. Washington State Department of Natural Resources, Olympia, WA

Dethier MN, Schoch GC (2005) The consequences of scale: assessing the distribution of benthic populations in a complex estuarine fjord. Estuar Coastal Shelf Sci 62:253-270

Ellis D (1985) Taxonomic sufficiency in pollution assessment. Mar Pollut Bull 16:459

Fauchald K, Jumars PA (1979) The diet of worms: a study of polychaete feeding guilds. Oceanogr Mar Biol Ann Rev $17: 193-284$

Ferraro SP, Cole FA (1990) Taxonomic level and sample size sufficient for assessing pollution impacts on the Southern California Bight macrobenthos. Mar Ecol Prog Ser 67: 251-262

Ferraro SP, Cole FA (1992) Taxonomic level sufficient for assessing a moderate impact on macrobenthic communities in Puget Sound, Washington, USA. Can J Fish Aquat

Editorial responsibility: Lisa Levin (Contributing Editor), La Jolla, California, USA
Sci 49:1184-1188

Ferraro SP, Cole FA (1995) Taxonomic level sufficient for assessing pollution impacts on the Southern California Bight macrobenthos - revisited. Environ Tox Chem 6: 1031-1040

Frost TM, Carpenter SR, Kratz TK (1992) Choosing ecological indicators: effects of taxonomic aggregation on sensitivity to stress and natural variability. In: McKenzie DH, Hyatt DE, McDonald VJ (eds) Ecological indicators, Vol. 1. Elsevier, London, p 215-227

Gabrielson PW, Widdowson TB, Lindstrom SC, Hawkes MW, Scagel RF (2000) Keys to the benthic marine algae and seagrasses of British Columbia, southeast Alaska, Washington and Oregon. Phycol Contrib no.5, University of British Columbia, Vancouver

James RJ, Lincoln Smith MP, Fairweather PG (1995) Sieve mesh-size and taxonomic resolution needed to describe natural spatial variation of marine macrofauna. Mar Ecol Prog Ser 118:187-198

Kozloff EN (1983) Seashore Life of the Northern Pacific Coast. University of Washington Press, Seattle, WA

Kozloff EN (1996) Marine invertebrates of the Pacific Northwest. University of Washington Press, Seattle

Lasiak T (2003) Influence of taxonomic resolution, biological attributes and data transformations on multivariate comparisons of rocky macrofaunal assemblages. Mar Ecol Prog Ser 250:29-34

Mistri M, Rossi R (2001) Taxonomic sufficiency in lagoonal ecosystems. J Mar Biol Assoc UK 81:339-340

Olsgard F, Somerfield PJ, Carr MR (1997) Relationships between taxonomic resolution and data transformations in analyses of a macrobenthic community along an established pollution gradient. Mar Ecol Prog Ser 149:173-181

Pagola-Carte S, Urkiaga-Alberdi J, Bustamante M, SaizSalinas JI (2002) Concordance degrees in macrozoobenthic monitoring programmes using different sampling methods and taxonomic resolution levels. Mar Pollut Bull 44:63-70

Ponti M, Abbiata M (2004) Quality assessment of transitional waters using a benthic biotic index: the case study of the Pialassa Baiona (northern Adriatic Sea). Aquat Conserv Mar Freshw Ecosyst 14:S31-S41

Rakocinski CF, Brown SS, Gaston GR, Heard RW, Walker WW, Summers JK (1997) Macrobenthic responses to natural and contaminant-related gradients in northern Gulf of Mexico estuaries. Ecol Appl 7:1278-1298

Rumohr H, Karakassis I (1999) Comparison of multivariate patterns: different taxonomic levels in macrofaunal analysis versus sediment profiling imagery (SPI). Mar Ecol Prog Ser 190:125-132

Sokal RR, Rohlf FJ (1995) Biometry: the principles and practice of statistics in biological research. Freeman, New York

Somerfield PJ, Clarke KR (1995) Taxonomic levels, in marine community studies, revisited. Mar Ecol Prog Ser 127: 113-119

Warwick RM (1988a) The level of taxonomic discrimination required to detect pollution effects on marine benthic communities. Mar Pollut Bull 19:259-268

Warwick RM (1988b) Analysis of community attributes of the macrobenthos of Frierfjord/Langesundfjord at taxonomic levels higher than species. Mar Ecol Prog Ser 46:167-170

Submitted: January 14, 2005; Accepted: July 16, 2005

Proofs received from author(s): December 7, 2005 